\title{
Hiekkaa rattaissa?
}

\section{Siirtolaisuus ja turvapaikan- hakijat suomalaista korkeakoulu- järjestelmää kehittämässä}

\author{
$y$ \\ Suomalainen korkeakoulujärjestelmä on hioutunut \\ palvelemaan vakiintuneita kohderyhmiä. \\ Turvapaikanhakijoiden koulutuksellinen tasa-arvo \\ ei sen puitteissa tunnu toteutuvan.
}

LEIKITTELEN TOISINAAN AJATUKSELLA siitä, miten akateemisesti koulutettuna ja runsaasti työkokemusta hankkineena aikuisena selviytyisin tilanteessa, jossa kotimaahan ei enää olisi paluuta. Asetun mielessäni maailmankartalla paikkaan, jossa nyt osaamiani kieliä ei käytetä. Miten voisin sielläkin tulla toimeen, huolehtia läheisistäni ja hyödyntää jo olemassa olevaa osaamistani? Entä jos joutuisin ensin odottamaan vuosia päätöstä siitä, saanko edes jäädä?

Ajassamme moni aikuinen pohtii samoja kysymyksiä ajatusleikin sijaan osana oman elämänsä arkea - myös paikassa nimeltä Suomi.

Reilun vuoden ajan minulla oli kollegojeni kanssa mahdollisuus tarkastella erityisesti suomalaista korkeakoulutuskenttää yhdessä muualta tulleiden kanssa. Ohjasimme Suomeen syystä tai toisesta päätyneitä, usein Euroopan ulkopuolella syntyneitä, korkeakoulutettuja tai korkeakoulutuksesta kiinnostuneita aikuisia kahdessa kansallisessa Supporting Immigrants in Higher Education in Finland (SIMHE) -pilottihankkeessa. Samalla pääsimme aitiopaikalle ihmettelemään niitä kantasuomalaisilta usein kätköön jääviä haasteita, joita koulutusjärjestelmäämme on - tietoisesti tai tiedostamatta - rakennettu.

SIMHE-pilottihankkeet syntyivät opetus- ja kulttuuriministeriön (OKM) vuonna 2015 asettaman ohjausryhmän toimenpide-ehdotuksesta nimetä vastuukorkeakouluja osallistumaan "jo varhaisessa 
KOUlutuspolittineN HALU

HOUKUTELLA MAKSUKYKYISI $\ddot{A}$

KANSAINV $\ddot{A} L I S I \ddot{A}$

HUIPPUOSAAJIA ON SUURI.

vaiheessa korkeakoulutettujen maahantulijoiden osaamisen tunnistamiseen sekä ohjaamaan henkilöitä jatkokoulutukseen ja työelämään” (OKM 2016, 25).

Nykyisellään kansallista SIMHE-palvelua tarjotaan strategisen rahoituksen turvin kuudessa vastuukorkeakoulussa. Verkostoon kuuluvat toimintaa jo pilotoineiden Jyväskylän yliopiston ja Metropolia ammattikorkeakoulun lisäksi Turun ja Helsingin yliopistot sekä Karelia ammattikorkeakoulu ja Oulun ammattikorkeakoulu (OPH 2017a).

Toiminta kehittyy yhä, ja sen vakiinnuttaminen ottaa aikansa, mutta työn tavoitteena on "nopeuttaa ja sujuvoittaa maahan tulleiden ja maassa jo olevien kansainvälisten henkilöiden korkeakouluopintoihin pääsyä” (OKM 2017b, 15, 46).

Tarkastelen seuraavassa suomalaista korkeakoulujärjestelmää ja sen käytäntöjä erityisesti Jyväskylän yliopistosta käsin toteutetun SIMHE-UniPID-pilottihankkeen (Häkkinen, Käyhkö \& Bogdanoff 2017) kokemusten pohjalta.

\section{KEITÄ OPISKELU SUOMALAISESSA KORKEAKOULUSSA SAA KIINNOSTAA?}

Valtaosa eli 73 prosenttia Finnish University Partnership for International Development (UniPID) -verkoston SIMHE-ohjauspalvelua käyttäneistä 130 henkilöstä oli turvapaikanhakijoita tai hiljattain pakolaisstatuksen saaneita. Useimmiten ohjaukseen hakeutui äidinkielenään arabiaa puhuva, noin 30-vuotias henkilö, jolla oli jo aiempia korkeakouluopintoja tai suoritettu tutkinto ja todistukset mukanaan. Etenkin tietotekniikka ja kaupallinen ala olivat vahvasti esillä, mutta kaiken kaikkiaan koko OKM:n ohjauksen alojen kirjo tuli katetuksi.
Yksilöohjaukseen hakeutuneiden sukupuolijakauma oli varsin tasainen, ja iältään he olivat 17-53-vuotiaita. Joukkoon mahtui yksittäisiä juuri lukionsa suorittaneita mutta myös joitakuita jo merkittävän akateemisen uran tehneitä. Tulkkia tarvittiin vain harvoin. (Häkkinen ym. 2017.)

Eri puolilta Suomea löytyi monipuolinen joukko motivoituneita aikuisia, joilla oli hyvät opiskeluedellytykset. Ainakaan heihin eivät stereotyyppiset ennakko-oletukset turvapaikanhakijoiden haluttomuudesta ja kyvyttömyydestä yliopisto-opintoihin (ks. Peltonen 2016, 18-21) päteneet.

Lukiokoulutukseen valmistavaa koulutusta lukuun ottamatta Suomen lainsäädännössä ei opetusja kulttuuriministeriön selvityksen (OKM 2017a) mukaan ole estettä valintakriteerit täyttävän turvapaikanhakijan opiskelijaksi ottamiselle. Käytännössä turvapaikanhakijan status sulkee kuitenkin yhä monien oppilaitosten ovet. Haasteita on myös maassa jo pidempään eri syistä oleskelleilla. Tiukat kotimaisten kielten tasovaatimukset ja vuoden 2017 aikana käyttöön otetut lukuvuosimaksut Euroopan unionin ja ETA-maiden ulkopuolelta tuleville englanninkielisten ohjelmien opiskelijoille saivat useita päteviä hakijoita siirtämään opiskelusuunnitelmansa tuonnemmaksi. Jotakin oleellista tilanteesta kuvaa toistuvasti kuultu huokaus "Suomeen on helpompi päästä opiskelemaan suoraan ulkomailta kuin tällä paikan päällä jo ollessaan”.

Korkeakoulujärjestelmämme on hiottu palvelemaan ensisijaisesti suomea tai ruotsia äidinkielenään puhuvia nuoria aikuisia ja toissijaisesti niin sanottuja kansainvälisiä opiskelijoita, jotka tulevat Suomeen vaihtoon, suorittamaan erillisen maisterintutkinnon tai tekemään väitöskirjaansa englanniksi.

Koulutuspoliittinen halu houkutella opiskeluvaiheessa mielellään maksukykyisiä "kansainvälisiä huippuosaajia" Suomeen on suuri (ks. OKM 2017c, 26-27). Vielä ei kuitenkaan tunnisteta niitä huippuosaajia, jotka jo oleskelevat Suomessa ja ponnistelevat aktiivisesti asettuakseen maahamme. Yhtäällä houkuttelemme huippuja tulemaan ja toisaalla teemme tiukan keskustelun siivittämiä päätöksiä, joilla pyritään vähentämään Suomen houkuttelevuutta ei-toivotumpien tulijoiden silmissä. Entä mitä 
kertoo koulutuksellisesta tasa-arvostamme se, että haluamme tarjota mahdollisuuksia vain valikoiduille huipuille?

Suomessa asuu kasvava joukko akateemisesti suuntautuneita aikuisia, joille suomi tai ruotsi on vasta toinen, kolmas tai jopa kuudes kieli ja joista joillekuille englanti ei vielä kuulu kielivalikoimaan. Muun muassa rekrytointi-, haku-, opiskelijavalintaja ohjauskäytännöissämme nämä henkilöt koetaan yhä valitettavan usein harmillisina poikkeuksina tai erityistapauksina, joihin ei oikeastaan olisi varaa ja joita varten ei ole erillisiä kirjattuja toimintaohjeita.

Pyrkiessään etenemään järjestelmämme toisiaan pyörittävien hammasrattaiden ja huolellisesti rakennettujen prosessikaavioiden läpi he aiheuttavat ratinaa kuin hiekanjyväset. Kuitenkin heidän joukossaan on monia, pitkälle opiskelleita eri alojen osaajia, joille on voinut kertyä työkokemustakin useasta maasta. Joillakin on taskussaan valmis tutkinto tai useita tutkintoja, jonka päälle he haluavat rakentaa uutta. Toisilla kandidaattivaiheen opinnot ovat jääneet kesken, ja tavoitteena on saattaa ne päätökseen. Joku tahtoo aloittaa aivan uuden uran. He ovat ammattilaisia, isiä, äitejä, setiä, tätejä, isoveljiä ja -siskoja, jotka toimivat roolimalleina monille itseään nuoremmille.

Siirtolaisten koulutususko on Suomessakin suurta (Rinne \& Tuittu 2011,39-95), mutta lapset lukevat paitsi vanhempiensa ja sukujensa toiveita myös perheidensä elämää. Jos isä, entinen turva-alan pääjohtaja, ei perheen nykyisessä asuinmaassa saa lisäkoulutuksenkaan jälkeen työtä edes talonmiehenä tai korkeakoulutettu äiti joutuu tyytymään kouluavustajan tehtäviin, rivien väliin jää kovin paljon luettavaa niin jälkikasvulle kuin yhteiskunnallekin. Turhautuminen syö voimavaroja ja ruokkii mahdollista ääriajattelua. Siirtolaiset ovat moninainen joukko, joka koostuu omia yksilöllisiä polkujaan etsivistä ihmisistä. Kaikki maahamme tulevat aikuiset siirtolaiset - turvapaikanhakijat ja pakolaiset mukaan luettuina - eivät ole kiinnostuneita kouluttautumisesta, ja ainakin aluksi koko aikuisiällä opiskelu voi tuntua kummalliselta ajatukselta. Silti ohjattavamme todistivat Suomen maineen hyvänä koulutusmaana kiirineen Euroopan rajojen ulkopuolellekin, ja yhä useampi nykyisistä siirtolaisistamme ja heidän jälkeläisistään on kiinnostunut opiskelemaan suomalaisessa korkeakoulussa. Miten otamme tämän huomioon ohjaustilanteissa, koulutussuunnittelussa, hakuprosesseissa ja koulutuspoliittisessa päätöksenteossa?

\section{JÄRJESTELMÄ SUODATTAA SIIRTOLAISOPISKELIJAT}

Siirtolaistaustaisten opiskelijoiden puute yliopistoissamme etenkään niin kutsutuilla säännellyillä aloilla (OPH 2017b) ei johdu pelkästä potentiaalisten opiskelijoiden mielenkiinnon puutteesta, heikosta kielitaidosta tai akateemisesta pystymättömyydestä.

Kehitettävää on myös itse järjestelmässä. Moninkertaisine filttereineen se suodattaa siirtolaisopiskelijat tehokkaasti pois niiltäkin aloilta, joiden asiantuntijatehtävissä heistä olisi huutava pula. (Vrt. Hoffman \& Piepponen 2017.)

Tuoreet viralliset linjaukset puhuvat korkeakoulutuksen ja tutkimuksen kansainvälisyyden, kulttuurisen moninaisuuden sekä liikkuvuutta ja maahan asettumista edistävien palvelujen puolesta (OKM 2017c, 25-28). Näiden muotoiluiltaan "transnationaalisen akateemisen kapitalismin" (ks. Hoffman, Nokkala \& Välimaa 2017) eli kansainvälisen kilpailun ja hyödyntavoittelun sävyttämien tavoitteiden toteutuminen käytännössä on vielä kaukana.

Vaikuttaa lisäksi siltä, että kansainvälisyyden edistämisen linjauksia kirjattaessa ei ole lainkaan ajateltu maahan jo muuttaneita potentiaalisia opiskelijoita ja tutkijoita. Entä miten esimerkiksi koulutuksen planetaarista vastuuta usein pohtivan professori Anja Heikkisen (2017) peräänkuuluttama jakaminen ja huolenpito saataisiin mukaan kuvaan?

Nykyinen järjestelmämme jarruttaa eri kategorioihin erityisesti oleskeluluvan perusteella niputettujen siirtolaisten koulutus- ja työllistymisprosesseja monella eri tasolla. Oleskeluluvan saanutta, korkeakoulusuuntautunutta henkilöä kehotetaan härkäpäisesti hakeutumaan ammatilliseen koulutukseen tai yrittäjäksi. Intensiivinen opiskelu, joka ei suoraan tuota tutkintoa, tipauttaa henkilön kaikkien tukien ulkopuolelle. Yksittäiselle kurssille saa osallistua vain, ellei suorita opintopisteitä. Hakulomakkeessa vaaditaan sosiaaliturvatunnusta tai passin numeroa, 
TIETO HYVISTÄ KÄYTANNÖISTÄ

EI AINA KULJE EDES

ORGANISAATION SIS ̈̈LLÄ.

joita ei hakuhetkellä vielä ole. Turvapaikanhakijastatuksella haetun ja saadun opiskelupaikan vastaanottaminen sidotaan turvapaikan saamiseen.

Hakuprosessissa ja pääsykokeissa etenkin muualta hankittu aiempi osaaminen jää yhä huomiotta, ja opiskelukielen kirjallisen ilmaisun hallinta korostuu. Englanniksi tutkintonsa Suomessa suorittaneidenkin työnsaanti riippuu paljolti suomen kielen osaamisesta. Korkeakoulujen kotimaisten kielten tarjontaa hiljattain kartoitettaessa kävi kuitenkin ilmi, että vaadittujen taitotasojen kielikursseja ei ole edes tarjolla (Saarinen, Vaarala, Haapakangas \& Kyckling 2016). Tarjonnan edistämiseksi suunnitellaan korkeakoulujen Virta-tiedonkeruuseen nyt suomi tai ruotsi toisena kielenä -opintojen opintopisteseurantaa (OKM 2017b, 30). Toivoa sopii, että opiskelijavalintauudistuksessa muistetaan nekin, jotka ovat suorittaneet lukion muualla kuin Suomessa ja joilla on jo aiemmin hankittua alan osaamista.

\section{KORKEAKOULUJEN HANKKEET JA PILOTIT HYVIEN KÄYTÄNTÖJEN TIENRAIVAAJINA}

Korkeakoulutuksemme kokonaiskuva oli monien SIMHE-UniPID-ohjauspalvelua käyttäneiden silmin katsottuna innostavista elinikäisen oppimisen lupauksistaan huolimatta edelleen käytännössä karu. Kuitenkin viime vuosina on tehty kiinnostavia pilotteja ja kehitetty käytäntöjä paitsi yksittäisissä oppilaitoksissa ja oppiaineissa myös alueellisesti ja kansallisesti. Rahoitettujen hankkeiden ja projektien vahvuutena näyttäytyy mahdollisuus kokeilla uutta, joskin myös heikkoudet ovat ilmeisiä: usein lyhyt ajallinen kesto ja jo etukäteen päätetyt tulokset eivät takaa todellista kehittämistä eivätkä pitkän aikavälin tuloksia. Lisäksi niin rahoitus kuin sen puutekin voivat lannistaa spontaania ruohonjuuritason toimintaa.
Jotkin pilotit kuitenkin onnistuvat sekä muuttamaan arkikäytäntöjä että vakiintumaan niiden osaksi. Näyttääkin siltä, että vuoden 2015 turvapaikanhakijat käynnistivät ja katalysoivat yllättävällä saapumisellaan monia prosesseja, joista on hyötyä myös maassa pidempään asuneille siirtolaisille ja koko koulutusjärjestelmällemme.

Vuonna 2016 ruotsinkielinen kauppakorkeakoulu Hanken mahdollisti Business Lead -ohjelmallaan 38 turvapaikanhakijan ja pakolaisstatuksen jo saaneen opinnot ja työelämään tutustumisen. Ohjelmaa toteutetaan parhaillaan toistamiseen (Heikkinen ym. 2017; Hanken \& SSE 2017).

Muuten opintopisteellistä yliopisto-opiskelua on päässyt maistamaan lähinnä yksiittäisillä opintojaksoilla avoimessa yliopistossa, kesäkoulussa, verkkokurssilla tai erillisen opinto-oikeuden turvin (Häkkinen ym. 2017). Tampereen seudulla Let's Work Together -toiminta on tarjonnut tilaa yliopiston, alueen muiden oppilaitosten ja toimijoiden, maassa jo kauemmin oleskelleiden siirtolaisten sekä turvapaikanhakijoiden yhteiselle tekemiselle ja vastausten etsinnälle (Heikkinen ym. 2017; Peltonen 2016; Peltonen \& Heikkinen 2017). Piloteista strategiseksi toiminnaksi muuttunut vastuukorkeakoulujen kansallinen SIMHE-palvelu tukee myös muita korkeakouluja näiden ponnisteluissa ja ohjaa potentiaalisia opiskelijoita soveltuviin koulutuksiin valtakunnallisesti.

Valitettavasti tieto hyvistä käytännöistä ei aina kulje edes saman organisaation sisällä, joten on tarpeen saattaa tietoa eri oppilaitoksissa jo tehdystä monipuolisesta työstä kootusti kaikkien ulottuville (ks. CIMO 2016; Käyhkö, Bontenbal \& Bogdanoff 2017; Häkkinen ym. 2017). Kohottamalla katsetta Suomen rajojen yli löytää lisää hyviä käytäntöjä puntaroitaviksi. Esimerkiksi yhä kehitysvaiheessa oleva Euroopan unionin EU Skills Profile Tool for Third Country Nationals -työkalu tarjoaa tukea osaamisen tunnistamiseen (EU 2017).

Hyvien käytäntöjen leviäminen on kuitenkin hidasta. Resurssipulan lisäksi ulottuvilla olevien käytäntöjen kokeilematta jättämisen syyksi nousi toistuvasti esiin korkeakoulukohtaisten ja kansallisten linjausten puute. Tähän linjausten kaipuuseen yhdistyy aitoa huolta siitä, ettei korkeakouluissa niiden 


\section{PANOSTAMINEN VAIN LASTEN}

JA NUORTEN NOPEAAN

KOTOUTUMISEEN EI RIIT $\ddot{A}$.

autonomisuudesta huolimatta vain tehtäisi mitään luvatonta. Oman organisaation strategia on sekin otettava huomioon. Ymmärrettävästi jo nykyisellään ylikuormitetussa tilanteessa ei haluta vapaaehtoisesti ryhtyä tekemään jotakin sellaista ylimääräistä, jolle ei mahdollisesti löydy tukea tai rahoitusta.

Skeptisesti ajateltuna säntillisesti kaikkialla Suomessa noudatettavat linjaukset ovat korkeakoulujen ja etenkin eri yliopistojen ja tiedekuntien keskuudessa harvassa. Miksi juuri siirtolaisten ja turvapaikanhakijoiden kohdalla hitaasti rakentuvat yhteiset linjaukset ovat tarpeen ennen käytännön toimiin ryhtymistä? Syntyy vaikutelma, että "ongelman" pitäisi poistua itsestään, kunhan kyselijät kattavia linjauksia aikansa odoteltuaan lopulta luopuvat turhista toiveistaan.

Eri yhteyksissä vuoden 2015 turvapaikanhakijat määrittyvät eräänlaiseksi massiiviseksi kertaeräksi, jonka "käsittelemisen" jälkeen voidaan palata takaisin "normiarkeen". Kansainvälisen liikkuvuuden ja siirtolaisuuden kysymyksiä työkseen tarkastelevat tutkijat ovat kuitenkin asiasta toista mieltä - uusia pakolaiskriisejä syntyy eri puolilla maailmaa lukuisista eri syistä (mm. UNHCR 2017).

Ihmiset liikkuvat tulevaisuudessakin paitsi maiden myös ammattien ja oppilaitosten välillä. Samalla korkeakoulujenkin opiskelija-aines moninaistuu moninaistumistaan. Järjestelmämme olisi siis päivitettävä "uuden normiarjen" tasalle ja mitä pikemmin, sen parempi. Nykyhetki vaikuttaa varsin otolliselta toimeen tarttumisen kannalta. Monia oleellisia muutosprosesseja onkin käynnissä, asiat ovat valmiiksi muun muassa opetus- ja kulttuuriministeriön sekä Opetushallituksen työpöydillä, ja rahoitustakin on löytynyt haettavaksi (OKM 2017d). Tarvitaan monia eri intressiryhmiä edustavia silmiä, ääniä ja käsiä rakentamaan kaivatuista linjauksista mahdollisimman toimivia.
KRIITTISTÄ AIKUISKASVATUSTA

VAI KONEISTONHUOLTOA?

Tyhjästä ei enää tarvitse aloittaa. Ammattikorkeakouluissa on seitsemän viime vuoden ajan järjestetty valmentavia opintoja antamaan maahanmuuttajille kielelliset ja muut tarvittavat valmiudet ammattikorkeakouluopintoja varten.

Valmentavien koulutusten käytännöt ovat tosin kirjavia, ja alavaihtoehtoja tarvittaisiin enemmän. Lisäksi valmentavien opintojen jälkeenkin korkeakoulupaikan saaminen on vaikeaa etenkin yliopistoissa. (Lepola 2017.) Kalliiden alakohtaisten valmennuskurssien ja aikuislukio-opintojen rinnalla yleisempää ja erityisesti yliopistoihin valmentavaa koulutusta on toistaiseksi ollut tarjolla lähinnä yksittäisten vapaan sivistystyön toimijoiden kautta (esim. Alkio-opisto 2017). Uudet alkavat hankkeet jatkavat kehitystyötä niin ammattikorkeakouluissa kuin yliopistoissakin (OKM 2017d).

Tie tutkinto-opiskelijaksi voi silti olla kovin pitkä. Yliopisto on ainoa portti monille tärkeille aloille, ja mikäli se pidetään siirtolaisosaajille suljettuna, varmistetaan samalla, että kyseisten alojen asiantuntijuus ei pääse maassamme moninaistumaan (vrt. Hoffman \& Piepponen 2017).

Nuorisotakuun tarjoamien mahdollisuuksien ja oppivelvollisuusikäisten itsestään selvän koulutuksen varjossa aikuinen siirtolainen ja erityisesti turvapaikanhakija on suuressa vaarassa jäädä Suomessa koulutusmarginaaliin. Ellei pääsyä ole sen enempää töihin kuin koulutukseenkaan, etenemisen mahdollisuudet ovat vähissä (vrt. Silvennoinen \& Nori 2014). Mikä sitten on aikuiskasvatuksen ammattilaisten rooli ja tehtävä suhteessa näihin koulutusmarginaaliin jo pudonneisiin tai putoamassa oleviin aikuisiin? Valitako kriittiselle perinteelle keskeinen yhteiskunnallisen oikeudenmukaisuuden tavoittelun tie (ks. Brunila \& Isopahkala-Bouret 2014) vai tyytyäkö insinöörinä huoltamaan olemassa olevaa koulutusjärjestelmäkoneistoa kontekstista piittaamatta, kuten kasvatuksen ja kasvatustieteen historiaan perehtynyt Antti Saari $(2011,17,27)$ pohtii?

Kriittisen aikuiskasvatusajattelun marinoimana käytännön toimijana ja aloittelevana tutkijana näen 
aikuiskasvatuksen ammattilaisten ja tutkijoiden erityisenä tehtävänä siirtolaiskysymyksissä sinnikkäästi muistuttaa päättäjiä siitä, ettei pelkkä lasten ja nuorten nopeaan kotoutumiseen panostaminen riitä. Myös heidän työikäiset vanhempansa ja muut aikuiset läheisensä on otettava todesta.

Lisäksi meidän tulisi rakenteellisia muutoksia pelkäämättä aktiivisesti etsiä keinoja, joilla todesta ottaminen tulee mahdolliseksi korkeakoulutuksenkin foorumeilla. Tämä edellyttää koulutuspoliittiseen päätöksentekoon vaikuttamista sen eri tasoilla omasta yksiköstä ja organisaatiosta alkaen, aina kansalliselle ja kansainväliselle tasolle saakka. Se merkitsee tilan antamista akateemisten siirtolaisten omalle asiantuntijuudelle, eri tahojen kohtaamisille, keskusteluille ja kuulluksi tulemisille - kenties aikuiskasvatuksen valtavirran ulkopuoliseenkin elämään paneutuneiden Kristiina Brunilan ja Ulpukka IsopahkalaBouretin (2014) sanoin "marginaalin voimaa”?

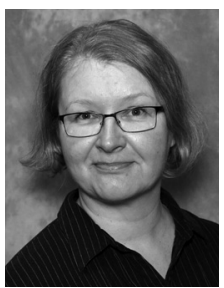

\section{KATINKA KÄYHKÖ}

KM, projektitutkija, UniPID, Jyväskylän yliopisto aikuiskasvatustieteen jatko-opiskelija, Itä-Suomen yliopisto

\section{LÄHTEET}

Alkio-opisto (2017). Maahanmuuttajien korkeakouluun valmentavan koulutuksen verkkosivut http:// www.alkio.fi/opintolinjat/maahanmuuttajienkorkeakouluun-valmentavat-opinnot. (28.6.2017)

Brunila, K. \& Isopahkala-Bouret, U. (2014). Marginaali säätelevänä ja tuottavana voimana. Teoksessa Brunila, K. \& Isopahkala-Bouret, U. (toim.) Marginaalin voima! Aikuiskasvatuksen 51. vuosikirja. Helsinki: Kansanvalistusseura, 23-37.

CIMO (2016). Korkeakoulujen tukitoimet pakolaisille ja turvapaikanhakijoille. Kooste taustakyselystä korkeakouluille. PowerPoint-esitys 2.9.2016 keskustelutilaisuudessa.

http://www.cimo.fi/instancedata/prime_product_ julkaisu/cimo/embeds//100725_JULKAISTAVA_ Korkeakoulujen_pakolaisten_tukitoimet_2016.pdf. (26.6.2017)

EU (2017). New Skills Agenda for Europe - EU Skills Profile Tool for Third Country Nationals -työkalun esittelysivu. http://ec.europa.eu/social/main.jsp?catld =1223\&intPageld=5019\&langld=en. (30.6.2017)

Hanken \& SSE (2017). Hanken \& SSE Executive Education Integration Program Business Lead for Educated Immigrants -ohjelma. http://www.hankensse.fi/ executive-education/social-impact. (28.6.2017)

Heikkinen, A. (2017). Sharing and Caring. Teoksessa Käyhkö, K., Bontenbal I., \& Bogdanoff M. (toim.) "Open the doors!": Migrants in Higher Education. Fostering Cooperation at Universities Seminar 13.-14.12.2016 in Jyväskylä. Jyväskylä: UniPiD \& Jyväskylän yliopisto, 25-26.
Heikkinen, A., Polsa, P., Crawford, S., Gräsbeck, C. Haltia N. \& Käyhkö, K. (2017). "Open or create?": providing study options for diverse students. Teoksessa Käyhkö, K., Bontenbal I., \& Bogdanoff M. (toim.) "Open the doors!": Migrants in Higher Education. Fostering Cooperation at Universities Seminar 13.-14.12.2016 in Jyväskylä. Jyväskylä: UniPiD \& Jyväskylän yliopisto, 54-60.

Hoffman, D. M., Nokkala, T. \& Välimaa, J. (2017). 'World Class Local Heroes' Emerging Competitive Horizons and Transnational Academic Capitalism in Finnish Higher Education - 2010-2012. Painossa.

Hoffman, D. \& Piepponen, S. (2017). Dilemmas that explain persistent exclusion in Finnish higher education. Teoksessa Käyhkö, K., Bontenbal I., \& Bogdanoff M. (toim.) "Open the doors!": Migrants in Higher Education. Fostering Cooperation at Universities Seminar 13.-14.12.2016 in Jyväskylä. Jyväskylä: UniPiD \& Jyväskylän yliopisto, 69-73.

Häkkinen, M., Käyhkö, K. \& Bogdanoff, M. (2017). "Enemmän kuin pelkkä projekti": Supporting Immigrants in Higher Education in Finland SIMHEUniPID. Pilottihankkeen yhteenveto. Jyväskylä: UniPID \& Jyväskylän yliopisto.

Käyhkö, K., Bontenbal, I. \& Bogdanoff, M. (toim.) (2017). "Open the doors!": Migrants in Higher Education. Fostering Cooperation at Universities Seminar 13.-14.12.2016 in Jyväskylä. Jyväskylä: UniPID \& Jyväskylän yliopisto. 
Lepola, L. (2017). Ammattikorkeakoulujen maahanmuuttajille järjestämä korkeakouluopintoihin valmentava koulutus vuosina 2010-2017. Kansallisen koulutuksen arviointikeskuksen julkaisu 2017:15. Helsinki: Kansallinen koulutuksen arviointikeskus. https://karvi.fi/app/uploads/2017/06/KARVI_1517.pdf. (22.06.2017)

OKM (2016). Maahanmuuttajien koulutuspolut ja integrointi - kipupisteet ja toimenpide-esitykset. Opetus- ja kulttuuriministeriön julkaisuja 2016:1. Helsinki: Opetus- ja kulttuuriministeriö.

OKM (2017a). Turvapaikanhakijoiden opiskelusta. Päivitetty 25.1.2017. Opetus- ja kulttuuriministeriö. http://minedu.fi/documents/1410845/4449678/ Turvapaikanhakijoiden_opiskelu/398c4305-47ff-4c739b23-4a64375ffaa6. (22.6.2017).

OKM (2017b). Maahanmuuttajien koulutuspolut ja integrointi - kipupisteet ja toimenpide-esitykset II. Opetus- ja kulttuuriministeriön julkaisuja 2017:5. Helsinki: Opetus- ja kulttuuriministeriö.

OKM (2017c). Yhteistyössä maailman parasta. Korkeakoulutuksen ja tutkimuksen kansainvälisyyden edistämisen linjaukset 2017-2025. Opetus- ja kulttuuriministeriön julkaisuja 2017:11. Helsinki: Opetus- ja kulttuuriministeriö.

OKM (2017d). Maahanmuuttajien koulutuspolkuja vauhditetaan. Opetus- ja kulttuuriministeriön tiedote 11.8.2017. http://minedu.fi/artikkeli/-/asset_publisher/ maahanmuuttajien-koulutuspolkuja-vauhditetaan. (16.8.2017)

OPH (2017a). Korkeakoulujen SIMHE-palvelut. http://www.cimo.fi/korkeakoulut_tukemassa_ maahanmuuttajia/simhe_palvelut. (16.8.2017)

OPH (2017b) Säänneltyjen ammattien luettelo. http:// www.oph.fi/koulutus_ja_tutkinnot/tutkintojen_ tunnustaminen/patevyys_ammattiin. (16.8.2017)
Peltonen, S. (2016). Eliittiporukka ja turvapaikanhakijat. Raportti turvapaikanhakijoiden osallistamisesta Tampereen yliopistossa. Tampere: Tampereen yliopisto. https://letsworktogetheredu.files.wordpress. com/2016/11/eliittiporukka-ja-turvapaikanhakijat_ raportti_muokattu-25-11-2016.pdf. (viitattu 22.7.2017)

Peltonen, S. \& Heikkinen, A. (2017). Summary of LWT (report and list of activities) 2016-2017. https:// letsworktogetheredu.files.wordpress.com/2017/06/ Iwt-reportandactivities.pdf (27.6.2017)

Rinne R. \& Tuittu A. (2011) Peruskoulu maahanmuuttajaja suomalaisvanhempien silmin. Vieraina koulussa? Monikulttuurinen koulu oppilaiden, vanhempien, opettajien ja rehtoreiden kokemana. Turku: Turun yliopisto, kasvatustieteiden tiedekunnan julkaisuja A:211, 39-95.

Saari, A. (2011). Kasvatustieteen tiedontahto. Kriittisen historian näkökulmia suomalaiseen kasvatuksen tutkimukseen. Suomen kasvatustieteellinen seura. Kasvatusalan tutkimuksia 55. Jyväskylä: Suomen kasvatustieteellinen seura.

Saarinen, T., Vaarala, H., Haapakangas, E.-L. \& Kyckling, E. (2016). Kotimaisten kielten koulutustarjonta kansainvälisille korkeakouluopiskelijoille. Jyväskylä: Jyväskylän yliopisto, Soveltavan kielentutkimuksen keskus.

Silvennoinen, H. \& Nori, H. (2014). Koulutuksen ja oppimisen marginaalissa. Teoksessa Brunila, K. \& Isopahkala-Bouret, U. (toim.) Marginaalin voima! Aikuiskasvatuksen 51. vuosikirja. Helsinki: Kansanvalistusseura, 102-127.

UNHCR (2017). Global Trends: Forced Displacement in 2016. http://www.unhcr.org/statistics/ unhcrstats/5943e8a34/global-trends-forceddisplacement-2016.html. (26.6.2017) 